6.

\title{
Método Taguchi para optimizar marcadores RAPD-PCR y determinar diversidad genética: un modelo, la tortuga cabezona Caretta caretta (Testudines: Cheloniidae)
}

\author{
Julio Martínez-Ortega \\ Universidad Jorge Tadeo Lozano \\ julcem013@gmail.com \\ Javier Hernández-Fernández \\ Universidad Jorge Tadeo Lozano \\ javier.hernandez@utadeo.edu.co
}

\section{Resumen}

Se implementó el método Taguchi para optimizar marcadores RAPD-PCR que permitan estimar la diversidad genética con el modelo: tortuga cabezona. Se aisló ADN de $C$. caretta de dos zonas del Caribe colombiano (Don Diego $\mathrm{N}=5$ e Islas del Rosario $\mathrm{N}=3$ ) y se cuantificó. Se aplicó una matriz ortogonal de Taguchi para estandarizar cuatro variables para la reacción RAPD-PCR. Los datos obtenidos se analizaron con el programa PopGen. Las condiciones estandarizadas se encontraron con 7,85 $\mathrm{ng} / \mu \mathrm{l}$ de ADN, 3,5 mM de $\mathrm{MgCl}_{2}, 200 \mathrm{mM}$ de dNTP's, 0,5 $\mu \mathrm{M}$ de oligonucleótido y una unidad de Taq ADN polimerasa, en un volumen final de reacción de $20 \mu \mathrm{l}$. Las condiciones de termociclado iniciaron a $94^{\circ} \mathrm{C}$ por $5 \mathrm{~m}$, seguido de 40 ciclos de: $94^{\circ} \mathrm{C}$ por $40 \mathrm{~s}, 37^{\circ} \mathrm{C}$ por $40 \mathrm{~s}$ y $72^{\circ} \mathrm{C}$ por $90 \mathrm{~s}$. Los marcadores se registraron en una matriz binaria de presencia (1) y ausencia (0), y como un ejemplo modelo se determinó la diversidad genética utilizando el índice de Shannon ( $H^{\prime}=0,44+/-0,27$ individuos de Don Diego y de $H^{\prime}=0,25+/-0,32$ para Isla del Rosario), el índice promedio de estructura genética ( $G s t=0,27)$ y el índice de migración efectiva $(N m=1,28)$. Se estandarizó una metodología haciendo uso del método de Taguchi que produce bandas claras, legibles y reproducibles, método que puede emplearse como alternativa confiable para realizar estudios de diversidad genética en la tortuga cabezona o de otras especies, y adicionalmente, integrarlos en el currículo de biología molecular y/o bioquímica para estudiantes de pregrado y maestría.

Palabras clave: método Taguchi, matriz ortogonal, RAPD-PCR, Caretta caretta, diversidad genética. 


\begin{abstract}
Implementation of Taguchi method to optimize RAPD-PCR Markers for determining the genetic diversity: an example the loggerhead turtle, Caretta caretta (Testudines:Cheloniidae). DNA was isolated from Caretta caretta two zone of the Colombian Caribbean (Don Diego $\mathrm{N}=5$ and Rosario Islands $\mathrm{N}=3$ ) and quantified it. Was applied a Taguchi orthogonal matriz of four variables to standardize RAPD-PCR reaction. The data were analyzed with the program PopGen. The conditions were standardized to $7.85 \mathrm{ng} / \mathrm{ml}$ of DNA, $3.5 \mathrm{mM} \mathrm{MgCl}$, $200 \mathrm{mM}$ dNTP's, $0.5 \mathrm{mM}$ oligonucleotide and one unit of Taq DNA polymerase in a final reaction volume of $20 \mathrm{ml}$. Thermocycling conditions initiated at $94^{\circ} \mathrm{C}$ for $5 \mathrm{~min}$, followed by 40 cycles of: $94^{\circ} \mathrm{C}$ for $40 \mathrm{~s}, 37^{\circ} \mathrm{C}$ for $40 \mathrm{~s}$ and $72^{\circ} \mathrm{C}$ for $90 \mathrm{~s}$. The markers were recorded in a binary matrix of presence (1) and absence (0), and as a model example of genetic diversity was determined using the Shannon index $\left(H^{\prime}=0.44+/-0.27\right.$ individuals and Don Diego $\mathrm{H}^{\prime}=0.25+/-0.32$ for Isla del Rosario), the average rate of genetic structure (Gst=0.27) and the effective migration rate $(\mathrm{Nm}=1.28)$. Methodology was standardized using Taguchi method that produces bands of light, legible and reproducible that can be used as a reliable alternative for studies of genetic diversity in the loggerhead turtle and other species, and further, integrate them into the curriculum of molecular biology and/or biochemistry for undergraduate and graduate students.
\end{abstract}

Key words: Taguchi, orthogonal matrix, RAPD-PCR, Caretta caretta, genetic diversity.

\title{
Índice temático
}

\section{Introducción}

Materiales y métodos

Análisis de datos

\section{$\underline{\text { Resultados }}$}

\section{Discusión}

\section{Conclusiones}

\section{$\underline{\text { Referencias }}$}




\section{Introducción}

El uso de marcadores moleculares basados en ADN ha revolucionado la genética animal y vegetal. Teóricamente, con los marcadores moleculares es posible analizar las variaciones genéticas en un genoma completo. Los más utilizados para realizar estudios de genética conservacionista, incluyen a las aloenzimas, ADN mitocondrial, RFLP, RAPD, AFLP, microsatélites, SNP y los marcadores EST. Los marcadores RAPD (del inglés: Random Amplification of Polymorphic DNA), han sido ampliamente manejados para detectar polimorfismos de ADN (Williams, Kubelik, Livak, Rafalski y Tingey; 1990; Welsh y McClelland, 1990) y en la caracterización genética y estimación de la diversidad de animales y plantas (Liu y Cordes, 2004; Eguiarte, Souza y Aguirre, 2007). Diversos estudios demuestran que existen factores que afectan los perfiles de amplificación obtenidos por RAPD-PCR (Atienzar, Evenden, Jha, Savva y Depledge, 2000), lo cual se manifiesta principalmente en falsos positivos (Jones et al., 1997) y la poca reproducibilidad de los ensayos (Poutou, Burbano, Sierra, Torre y Mercado, 1993).

Algunos de los principales factores que afectan estos perfiles de amplificación, son la calidad (Williams, Hanafey, Rafalski y Tingey, 1993) y la cantidad de ADN extraído (Staub y Serquen, 1996), así como las concentraciones de cloruro de magnesio $\left(\mathrm{MgCl}_{2}\right)$ (Penner et al., 1993) la Taq polimerasa (Yoon y Glawe, 1993), el programa de termociclado empleado -en específico, la temperatura de hibridación de los oligonucleótidos-iniciadores y el número de ciclos- (Marrugo y Vásquez, 2001) y la presencia de ARN contaminante (Ceballos, 1996).

Estas limitantes evidencian la necesidad de someter la técnica de RAPD-PCR a un proceso de puesta a punto, en el que se definan las condiciones desde las cuales los patrones obtenidos sean fiables y reproducibles.

En este estudio se describe una estrategia de optimización basado en modificación al método de Taguchi (Corpoguajira, 1992) y Taguchi y Wu (López, Carmona y Nichols, 2004), que contrasta con los problemas asociados con estrategias de optimización convencional (Cobb y Clarkson, 1994; López, Hernández y Bernal, 2008).

El método Taguchi se aprovecha en el diseño de procesos industriales, concretamente en el desarrollo de ensayos para establecer las condiciones deseables en procesos particulares realizando el mínimo número de experimentos (Cobb y Clarkson, 1994; Ministerio del Medio Ambiente de Colombia, 2000; Invemar, 2002). Taguchi (Corpoguajira, 1992) se sirve de ensayos 
progresivos. El primer experimento examina varios factores para identificar los que tienen un efecto importante. Estos factores de control predicen una combinación que dará lugar a un rendimiento óptimo. Hasta aquí los experimentos pueden ser suficientes para establecer una metodología, aunque es posible que exista la necesidad de hacer más experimentos (Cobb y Clarkson, 1994).

Los principios básicos de Taguchi (Corpoguajira, 1992; López et al., 2004) expuestos arriba, son aplicables a marcadores moleculares tipo RAPD-PCR, valiendo como filtro para examinar los efectos de todas las variables de reacción y la identificación de los factores con efectos principales sobre la amplificación, proceso realizable en un único ensayo con pocas reacciones. Por ejemplo, los experimentos de optimización rutinarios requieren que cada variable sea evaluada de forma independiente. Así, para estandarizar marcadores moleculares RAPD-PCR se puede necesitar la evaluación de cuatro componentes de la reacción (factores de control, 1-9) cada uno con tres niveles de concentración ( $A, B$ y $C$ ), que representarían 81 reacciones independientes.

Con métodos Taguchi (Corpoguajira, 1992; López et al., 2004), una estimación del efecto de cada componente podría llevarse a cabo usando solo nueve reacciones (tabla 1). El número de experimentos requerido (E) es calculado a partir de la ecuación [1].

$E=2 k+1$

Donde: $k$ es el número de factores a analizar.

Por lo tanto, en un experimento que demande estandarizar siete variables (i. e. concentración de DNA, $\mathrm{MgCl}_{2}$, Taq-DNA polimerasa, iniciadores, dNTPs, temperatura de anillamiento y número de ciclos) el número de reacciones requerido es 2187 (37). Sirviéndose del método Taguchi (Cobb y Clarkson, 1994; Corpoguajira, 1992) el número de reacciones se reduciría a solo $15(2 \times 7+1=15)$. En este estudio se tuvo como meta estandarizar marcadores moleculares RAPD-PCR aplicando los principios generales del método Taguchi (Corpoguajira, 1992; Cobb y Clarkson, 1994) para el modelo: tortuga marina Caretta caretta (Linnaeus, 1759). Siendo esta una especie que presenta un alto declive poblacional a causa de las diferentes presiones antrópicas que la rodean, por lo que actualmente está catalogada en peligro (EN) en el Libro rojo de reptiles de Colombia (Castaño, 2002). Además, es interesante para estudiar los índices de diversidad genética de Shannon, la estructura genética y el número de migrantes entre grupos, esto se realizó solo como modelo, debido al baja cantidad de muestras empleadas. 


\section{Materiales y métodos}

\section{Muestreo}

Se recolectaron muestras de sangre de los senos cervicales dorsales según la metodología previamente publicada (Dutton, 1996) de ocho individuos de dos grupos del Caribe colombiano, distribuidas de la siguiente forma: Islas del Rosario (tres individuos) y playa Don Diego (cinco individuos) (figura 1). Las alícuotas de sangre, se introdujeron en tubos Tris-EDTA buffer, (Greiner Bio-one®, Kremsmünster, Austria) para evitar la coagulación. Las muestras se transportaron a $4^{\circ} \mathrm{C}$ para su preservación antes de los análisis.

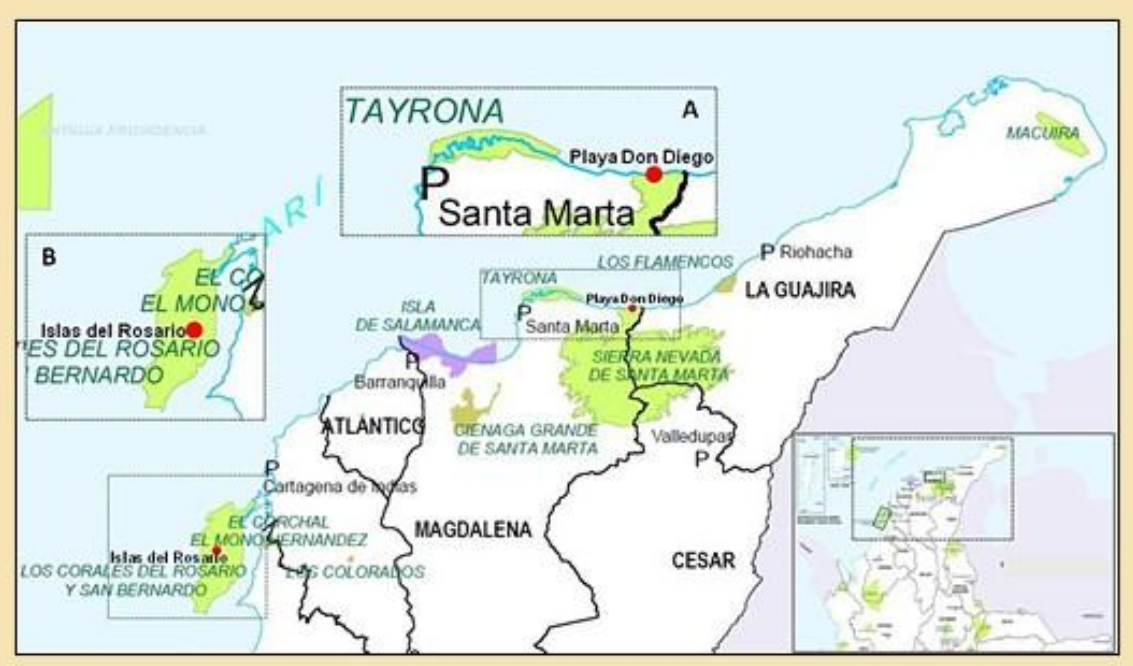

Figura 1. Mapa del área de estudio señalando las zonas de anidación (A) playa Don Diego; y zona de alimentacion (B) Islas del Rosario, donde fueron colectadas las muestras de la tortuga cabezona. Fuente: Modificado de Instituto Geográfico Agustin Codazzi, 2010).

\section{Extracción y cuantificación de ADN}

Se extrajo ADN total, empleando el kit UltraCleanTM Tissue \& Cells DNA Isolation (MO BIO, Laboratorios Inc. California, EE. UU.) siguiendo las especificaciones de la casa comercial fabricante. El ADN, se reveló después de una electroforesis en gel de agarosa al 1\%, y se coloreó con bromuro de etidio $(2 \mu \mathrm{g} / \mathrm{ml})$. El gel se fotografió con el fotodocumentador UVP GelDoc-lt ${ }^{T M}$ System y se analizó con el programa VisionWorks LS Image Acquisition and Analysis Software (UVP, Upland, EE. UU.). Después, se determinó la concentración del ADN con el equipo NanoDrop 1000 
Spectrophotometer y se registró con el programa ND-1000 V3.7.1 (Thermo Scientific, Denver, EE. UU.).

\section{Estandarización de RAPD-PCR}

Se recurrió a los principios generales del método Taguchi (Corpoguajira, 1992; Cobb y Clarkson, 1994) con el fin de disminuir el número de reacciones necesarias para obtener la primera aproximación de estandarización de marcadores moleculares RAPD-PCR utilizando DNA genómico de Caretta caretta (Yeh, Yang y Boyle, 1999). Se construyó una matriz ortogonal con las cuatro variables evaluadas (concentraciones de Taq ADN polimerasa, $\mathrm{ADN}, \mathrm{MgCl}_{2}$ y oligonucleótidoiniciador) con tres concentraciones diferentes cada una, proponiendo de esta forma la realización de nueve reacciones de 81 posibles (tabla 1). De estas nueve reacciones se seleccionó la que produjo el mayor número de bandas claras y legibles, y con estas condiciones se evaluaron independientemente cuatro variables para mejorar el bandeo producido por el oligonucleótidoiniciador OPA5: concentraciones de 0,59 a 7,85 ng de ADN, 2 a $4 \mathrm{mM}$ de $\mathrm{MgCl}_{2}, 1$ a 6 unidades de Taq ADN polimerasa y de 0,1 a 0,5 $\mu \mathrm{M}$ de oligonucleótidos-iniciadores. Con las condiciones de reacción optimizadas se evaluaron ocho decameros-iniciadores (OPA, Operon Technologies Inc. Almeda California, EE. UU.) (OPA1 a OPA10), con el fin de determinar la variabilidad existente en los ocho individuos analizados y en los oligonucleótidos-iniciadores mencionados. Además, se examinó la reproducibilidad de la técnica RAPD-PCR con el oligonucleótido-iniciador OPA4 haciendo uso de ADN de la tortuga CSM anidante de la playa Don Diego. Se realizaron reacciones de amplificación en días diferentes, se revelaron en agarosa al 1\% y se compararon de acuerdo con su perfil electroforético.

En todas las reacciones se usó Taq ADN polimerasa y dNTPs de la casa comercial Bioline Inc. (California, EE. UU.). Las reacciones se llevaron a cabo en un termociclador de bloque PTC-100 Programmable Thermal Controller (MJ Research, Madison, EE. UU.). Los productos de amplificación se revelaron en una cámara de electroforesis Gel XL ultra V-2 (Labnet International, Inc. Bioscience Research, Nueva Jersey, EE. UU.) y en geles de agarosa (Seaken al 2,5\%), por 90 minutos a 100 voltios. Los geles fueron fotografiados con el fotodocumentador UVP Gel-Doc-ITTM Imaging System (UVP LSC, Upland, EE. UU.). 


\begin{tabular}{|lllllllll|}
\hline Reacciones & 1 & $\mathbf{2}$ & $\mathbf{3}$ & $\mathbf{4}$ & Oligo. (mM) & ADN (ng) & MgCl2 (mM) & Taq Pol (unid) \\
\hline 1 & A A & A & A & 0,25 & 3 & 3 & 2 \\
2 & B & B & B & A & 0,375 & 6 & 2,5 & 2 \\
3 & C & C & C & A & 0,5 & 9 & 2 & 2 \\
4 & A & B & C & B & 0,25 & 6 & 2 & 3 \\
5 & B & C & A & B & 0,375 & 9 & 3 & 3 \\
6 & C A & B & B & 0,5 & 3 & 2,5 & 3 \\
7 & A & C & B & C & 0,25 & 9 & 2,5 & 5 \\
8 & B A & C & C & 0,375 & 3 & 2 & 5 \\
9 & C & B & A & C & 0,5 & 6 & 3 & 5 \\
\hline
\end{tabular}

Tabla 1. Matriz ortóloga de cuatro variables con tres niveles de concentración.

Fuente: Codd y Clarkson (1994).

La parte superior izquierda indica, las cuatro variables empleadas para la estandarización preliminar (oligonucleótidos-iniciadores, ADN molde, cloruro de magnesio $\left(\mathrm{MgCl}_{2}\right)$ y Taq ADN polimerasa) y las letras A, B y C expresan las diferentes concentraciones manejadas en cada una de las variables.

\section{Análisis de datos}

Bandas claras, nítidas y reproducibles fueron elegidas para los análisis. Los loci seleccionados fueron leídos y organizados en matrices binarias donde 1 indicó presencia y 0 ausencia. El estudio de las matrices generadas se realizó como un modelo aplicable a la genética de poblaciones, mediante el programa PopGen versión 3.2 (Nei, 1978) con el que se determinó la diversidad genética, a partir de la ecuación [2].

$H^{\prime}=2 q_{j}(i)[1-q(i)]$

Donde: $H^{\prime}$ es la medida convencional de la diversidad genética, siendo $2 q$ la probabilidad de que dos genes encontrados aleatoriamente en la población $j$, sean diferentes en el locus $i$. 
Además se estimó el índice de estructura genética Gst (Wright, 1978), que proporciona información sobre la divergencia genética y es el equivalente multialélico del Fst o índice de fijación (Dice, 1945). El valor Gst se vinculó con el número de migrantes Nm. Así mismo se calculó el índice de similaridad (Taguchi y Wu, 1980) y se realizó un ordenamiento con ayuda de la estrategia aglomerativa jerárquica de la media no ponderada (UPGMA), con el objetivo de establecer la similaridad genética entre individuos de los grupos y dentro de los grupos.

\section{Resultados}

\section{Descripción y estandarización por método Taguchi}

Se obtuvo ADN de buena calidad, concentración y pureza. La figura 2 muestra los productos de ADN obtenidos de los ocho individuos analizados. Se observan bandas únicas y limpias que presentan intensidades diferentes, en el carril 4 la muestra CSM4 revela la mayor intensidad que está relacionada directamente con la concentración de ADN (110 $\mathrm{ng} / \mu \mathrm{l})$; los carriles 6,7 y 8 evidencian menor intensidad de las bandas y, por ende, menor concentración de ADN (30, 43 y 41 $\mathrm{ng} / \mathrm{\mu l}$ respectivamente). Las otras muestras (carriles 1, 2, 3 y 5) manifestaron intensidades y concentraciones de ADN intermedias (entre $56-78 \mathrm{ng} / \mu \mathrm{l})$.

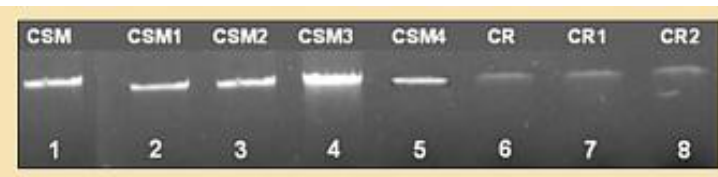

Figura 2. Productos de extracción de ADN de individuos de la tortuga marina Caretta caretta revelados en gel de agarosa al $1 \%$ y con bromuro de etidio. CSM: tortugas provenientes de la playa Don Diego; CR: tortugas de Islas del Rosario.

La estandarización de punto de partida fue hecha con matrices ortólogas de Taguchi mediante reacciones de ensayo y error que permitieron minimizar de 81 a nueve el número de reacciones (tabla 1). Se obtuvieron 58 fragmentos de marcadores RAPD-PCR con pesos moleculares entre 350 y 1.800 pares de bases (pb) (figura 3). Los carriles 1, 2, 8 y 9 presentaron el mismo patrón de amplificación, produciendo bandas nítidas y claras entre 350 y 1000 pb, además de no presentar bandas entre 1.000 y $1.800 \mathrm{pb}$. En los carriles 3 y 6 se dieron barridos entre 1.000 y $1.800 \mathrm{pb}$ y de ocho a nueve bandas entre 350 y 1.100 pb; en el carril 4 (figura 3) bandas claras y nítidas se 
evidenciaron entre 1.000 y $1.800 \mathrm{pb}$ y los barridos entre 350 y $1.000 \mathrm{pb}$, contrario a lo ocurrido en los carriles mencionados. Finalmente los carriles 5 y 7 mostraron patrones similares de bandeo entre 350 y $1.800 \mathrm{pb}$, pero debido a las bandas poco claras entre 400 y $600 \mathrm{pb}$ y entre 1.600 y $1.800 \mathrm{pb}$ amplificadas y reveladas en el carril 7 y menor número de bandas producidas en el carril 9 . Se observó que la reacción en el carril 5 descubrió las mejores condiciones de reacción para utilizar como punto de partida, produciendo el mayor número de bandas (Yoon y Glawe, 1993) y los patrones más claros y nítidos de las nueve reacciones evaluadas (tabla 1). En general, se puede afirmar que el método de Taguchi (Corpoguajira, 1992; Cobb y Clarkson, 1994) no solo disminuye la proporción de reacciones, también ahorra tiempo y economiza reactivos (Nason, 2002). Esta evaluación y el análisis se ejecutaron en dos días.

\section{Estandarización de las condiciones de amplificación por RAPD-PCR}

En la figura 4A se observan cambios en los patrones de los marcadores RAPDs para un vasto rango de concentraciones de ADN molde, el patrón de bandas más claro fue evidente para la concentración de 7,8 ng ADN molde (figura 4A carril 1). La figura 4B muestra el efecto de diferentes concentraciones de $\mathrm{MgCl}_{2}$ sobre los productos amplificados por RAPDs, en el carril 4 se comprueba el mejor perfil electroforético obtenido $\left(3,5 \mathrm{mM}\right.$ de $\left.\mathrm{MgCl}_{2}\right)$ ya que amplificó 11 fragmentos claros e intensos con pesos moleculares entre 400 y $1.900 \mathrm{pb}$. En los carriles 1, 2 y 3 con concentraciones de 2, 2,5 y $3 \mathrm{mM}$ de $\mathrm{MgCl}_{2}$ respectivamente, las bandas electroforéticas entre 400-800 pb son similares a las obtenidas en el carril 4; sin embargo, las bandas entre 800 y $1.900 \mathrm{pb}$ se presentan como un barrido inespecífico. En cambio, en el carril 5 con $7,5 \mathrm{mM}$ de $\mathrm{MgCl}_{2}$ se mejoró notablemente la nitidez de las bandas entre 800 y 1.900 pb, pero son significativamente más claras las conseguidas en el carril 4. Se determinó que la concentración óptima de Taq polimerasa fue de una unidad.

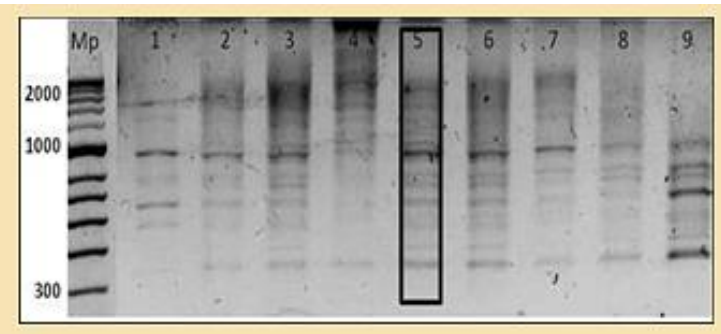

Figura 3. Amplificación por marcadores moleculares RAPDs de ADN de Caretta caretta, con método de Taguchi. Cada carril del 1 al 9 corresponde en el mismo orden a las reacciones presentadas en la tabla 1. Se emplearon $200 \mu \mathrm{M}$ de dNTPs y 1 X tampón de PCR en todas las reacciones. Mp: marcador de peso, Hyperladder II (Bioline Inc., California, EE. UU.). 

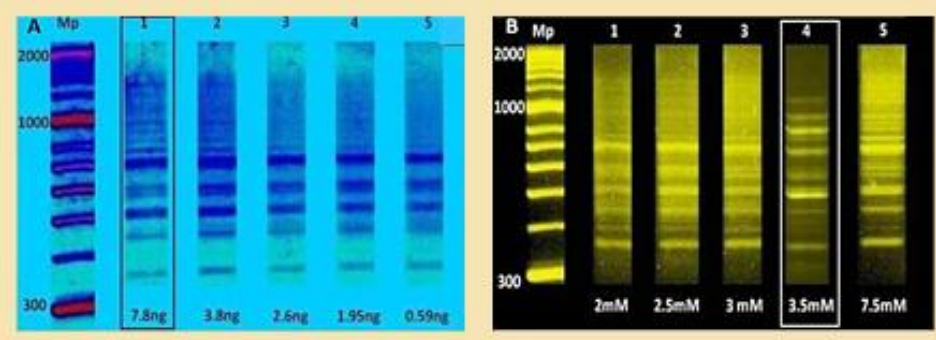

Figura 4. Efecto de diferentes concentraciones de $A D N$ molde $(A)$ y de cloruro de magnesio $(B)$ sobre la obtención de marcadores moleculares RAPDs de $C$. caretta. En la parte de abajo en cada carril aparecen las concentraciones de DNA y $\mathrm{MgCl}_{2}$ que se aplicaron. Se emplearon $200 \mu \mathrm{M}$ de dNTPs, $1 \mathrm{X}$ tampón de PCR, 0,375 $\mu \mathrm{M}$ de oligonucleótido-iniciador y tres unidades de Taq ADN polimerasa en todas las reacciones; en A se usó 3,0 mM de $\mathrm{MgCl}_{2}$ y en B. 7,8 ng de ADN molde. Mp: marcador de peso Hyperladder II (Bioline Inc., California, EE. UU.). (Cambio de color y contrastes con el programa VisionWorks LS Image Acquisition and Analysis Software, UVP, Upland, EE. UU., con la aplicación Image controls plug-in y pseudocolors plug-in).

Las concentraciones de oligonucleótido-iniciador que se aprovecharon en los carriles 2 y 3 produjeron un número de bandas intermedio (7 y 8 bandas), con barridos entre 1.000 y 1.400 pb (figura $5 \mathrm{~A}$ ), por el contrario, el carril 1 con una concentración de 0,1 $\mu \mathrm{M}$ arrojó el menor número de bandas (2) y de bajo peso molecular (300 a 400 pb), con poca intensidad y claridad. Los carriles 4 y 5 hicieron visible bandas más claras, nítidas e intensas. En el carril 4 se produjo un menor número de bandas (10). Por último se evaluaron cinco temperaturas de hibridación (figura 6B), debido a que esta variable es crucial para la PCR, pues ocurre la unión de los oligonucleótidos-iniciadores a la cadena molde y con ello el comienzo de la síntesis de la cadena complementaria. En los carriles 4 y 5 (temperaturas de 38 y $39^{\circ} \mathrm{C}$ respectivamente) se dieron bandas con buena intensidad entre 1.200 y 1.600 pb y nítidas entre 800 y 1.000 pb; estos cambios en los patrones amplificados permitieron determinar que la temperatura de $37^{\circ} \mathrm{C}$ es la más adecuada para la amplificación de marcadores RAPDs, ya que logró la mayor claridad, nitidez e intensidad en todas las bandas amplificadas (800 a $1.600 \mathrm{pb})$.
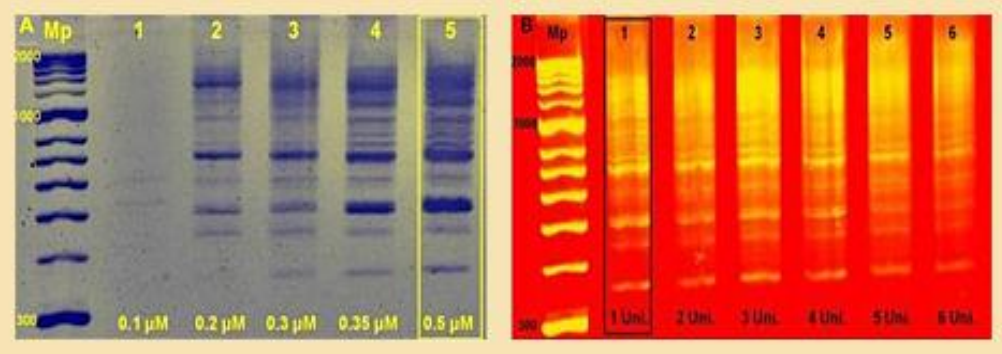

Figura 5. Influencia de las concentraciones de oligonucleótidos-iniciadores (A) y Taq polimerasa (B) sobre la obtención de marcadores moleculares RAPDs. Se usó en todas las reacciones concentraciones de $200 \mu \mathrm{M}$ de dNTPs, 1X tampón de PCR, 7,8 ng de ADN 
y 3,5 mM de $\mathrm{MgCl}_{2}$. En A: 3 unidades de Taq ADN polimerasa y en B: 0,5 $\mu \mathrm{M}$ de oligonucleótidos-iniciadores.

Mp: marcador de peso Hyperladder II (Bioline Inc., California, EE. UU.). (Cambio de color y contrastes con el programa VisionWorks LS Image Acquisition and Analysis Software, UVP, Upland, EE. UU., con la aplicación Image controls plug-in y pseudocolors plug-in).

\section{Variabilidad y reproducibilidad de la técnica de RAPD-PCR}

Las condiciones estandarizadas se provocaron con 7,85 $\mathrm{ng} / \mu \mathrm{l}$ de ADN, $3,5 \mathrm{mM}$ de $\mathrm{MgCl}_{2}, 200$ mM de dNTP's, 0,5 $\mu$ M de oligonucleótido y una unidad de Taq ADN polimerasa, en un volumen de reacción de $20 \mu \mathrm{l}$. Las condiciones de termociclado de la reacción se iniciaron con una desnaturalización a $94^{\circ} \mathrm{C}$ por $5 \mathrm{~m}$, seguida por 40 ciclos de: $94^{\circ} \mathrm{C}$ por $40 \mathrm{~s}, 37^{\circ} \mathrm{C}$ por 40 s y $72^{\circ} \mathrm{C}$ por $90 \mathrm{~s}$ y una fase de elongación final de $72^{\circ} \mathrm{C}$ por $5 \mathrm{~m}$.

Para confirmar que la reacción estandarizada con el oligonucleótido-iniciador OPA5, para obtener marcadores moleculares RAPDs con ADN genómico de Caretta caretta funcionaba igual con otros oligonucleótidos-iniciadores, se hizo un ensayo con ocho iniciadores OPA. En este ensayo se observaron bandas nítidas y claras en la mayoría de las reacciones obtenidas con los oligonucleótidos-iniciadores amplificados (figura $6 \mathrm{~A}$ ). Los carriles 2 y 3 muestran el bandeo electroforético de las reacciones donde se emplearon los oligonucleótidos-iniciadores OPA2 y OPA3, se observan barridos en las bandas entre 1.000 y $1.800 \mathrm{pb}$ y tenues entre 400 y $1.000 \mathrm{pb}$; en cambio, los carriles 1, 4, 5, 6, 7 y 8 en las reacciones que se usaron los oligonucleótidos OPA1, OPA4, OPA5, OPA6, OPA8 y OPA9 respectivamente, dieron como resultado bandas entre 350 y $2.000 \mathrm{pb}$ con buena nitidez y claridad. En el carril 9, la reacción en la que se utilizó el oligonucleótido-iniciador OPA10 no generó ningún producto de amplificación, debido quizá a que la secuencia nucleotídica de este iniciador no tiene sitios de hibridación u homología en el genoma de la tortuga cabezona. En la figura $6 \mathrm{~A}$ se manifiesta la variabilidad producida por los diferentes oligonucleótidos-iniciadores, que es el objetivo, cuando se estandariza un método para obtener RAPDs, este resultado es bien importante para alcanzar resultados robustos en el análisis genético poblacional de tortugas cabezonas. Analizando este, se observaron 83 bandas, las cuales fueron 15 monomórficas y 68 polimórficas, en adición, las flechas negras indican las bandas no informativas (monomórficas) (figura $6 \mathrm{~A}$ ) presentes en la mayoría de las reacciones con diferentes oligonucleótidos-iniciadores y con flechas rojas las bandas informativas (polimórficas) (figura 6A) únicas para la mayoría de oligonucleótidos-iniciadores amplificados. La metodología estandarizada 
con el oligonucleótido-iniciador OPA5, dio resultados similares en la obtención de RAPDs utilizando ADN de C. caretta en el $87,5 \%$ de los oligonucleótidos-iniciadores OPA evaluados.

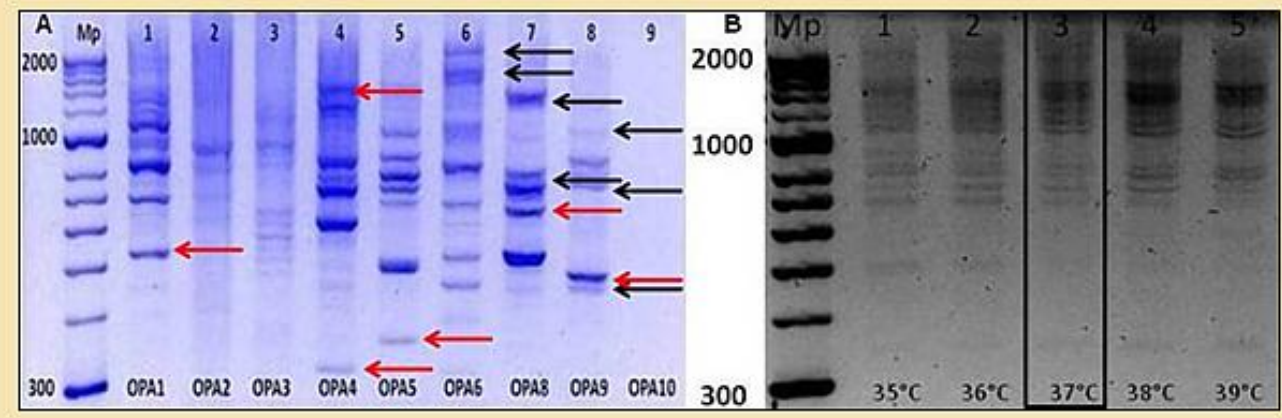

Figura 6. Variabilidad en el perfil electroforético de diferentes oligonucleótidos-iniciadores

OPA (A) (Operon Technologies Inc. Almeda California, EE. UU.) (A) y efecto de la temperatura en las condiciones óptimas de reacción utilizando ADN de la tortuga Caretta caretta (B).

Se manejaron las condiciones estandarizadas (ver texto) Mp: marcador de peso Hyperladder II (Bioline Inc., California, EE. UU.).

(Cambio de contraste en A con el programa VisionWorks LS Image Acquisition and Analysis Software, UVP, Upland, EE. UU., con la aplicación Image controls plug-in y pseudocolors plug-in).

En cuanto a la reproducibilidad del marcador RAPDs, la figura 7 visibiliza las amplificaciones realizadas en cuatro días diferentes; todos los carriles presentaron el mismo patrón de bandeo, respecto a intensidad, claridad y nitidez, además del número de bandas producidas (12) y el peso molecular entre 300 y $1.800 \mathrm{pb}$.

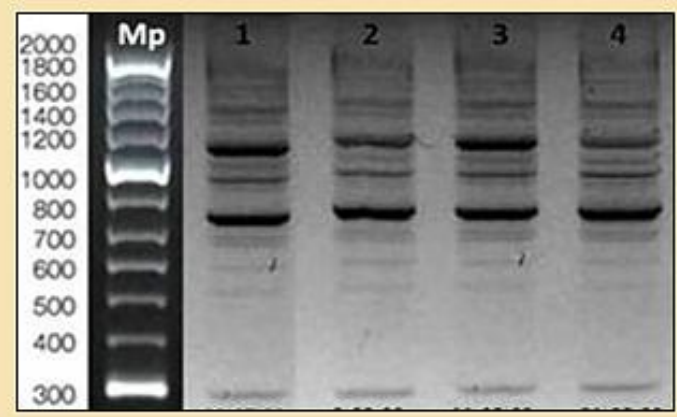

Figura 7. Reproducibilidad de marcadores RAPDs empleando las condiciones estandarizadas de reacción y el ADN del individuo CSM de playa Don Diego (ver texto). Se usó el oligonucleótido-iniciador OPA4

Mp: marcador de peso Hyperladder II (Bioline Inc., California, EE. UU.). 


\section{Análisis de marcadores como modelo para Caretta caretta}

En este estudio se determinaron algunas características genéticas que solo establecen resultados válidos para población, por lo que aquí se dan únicamente como evidencia de las posibilidades que brindan los marcadores RAPDs en este tipo de estudios. El análisis de los perfiles electroforéticos obtenidos se tradujo en una matriz de presencia (1) y ausencia (0), y con esta, se determinaron algunos parámetros genéticos. La diversidad de Shannon para las tortugas cabezonas provenientes de la playa Don Diego (Magdalena) fue de $H^{\prime}=0,4495+1-0,2764$ y para las tortugas provenientes de Islas del Rosario fue de $H^{\prime}=0,2535+/-0,3227$, mostrando una diversidad baja. E índice de estructura genética Gst es un indicador de la diversidad distribuida en los grupos (Nason, 2002). Los valores se encuentran entre 0 (cero), para el caso hipotético donde no hay divergencia genética entre dos grupos, y 1 (uno), para el caso extremo cuando se ha perdido o fijado un alelo para un locus determinado (Slatkin, 1987). El valor promedio de estructura genética para los dos grupos fue de $G s t=0,2799$, este valor ayuda a dar una idea aproximada de la escasa divergencia existente entre los dos grupos de tortugas. El índice de migración efectiva estima el número promedio de emigrantes de una generación a otra entre grupos (Abreu, 2000), para los individuos evaluados se obtuvo un valor alto de $N m=1,2862$, posiblemente debido a la fuerte filopatría que presentan las hembras y a la presencia de pocos machos reproductores $(40,41,44)$ en estas dos zonas del Caribe colombiano.

\section{Discusión}

\section{Estandarización de las condiciones de amplificación por RAPD-PCR}

Cavagnaro y Masuelli (2002) mencionan que la elevada sensibilidad de la reacción de PCR en la producción de marcadores RAPDs requiere cantidades de ADN molde diluidas con baja concentración de contaminantes, por esta razón, se realizaron diluciones en agua destilada y desionizada de 1:10, 1:20, 1:30, 1:40 y 1:50 de una muestra de ADN de Caretta caretta con una concentración final de $78,5 \mathrm{ng} / \mu \mathrm{l}$. Este ensayo buscaba disminuir el efecto inhibitorio de productos de ARN y polisacáridos que podrían estar en la muestra extraída de ADN y seleccionada para la optimización de la metodología. 
Al usar ADN molde en bajas concentraciones 3,9; 2,6; 1,95 y 0,59 ng (figura 4A carriles del 2 al 5), se arrojaron diferencias en el patrón de bandas amplificadas, como barridos entre los 900 y $1.800 \mathrm{pb}$ (carril 2), disminución en el número de bandas, intensidad y claridad, además de la no obtención de bandas entre 950 y 1.800 pb (carriles 3, 4 y 5). Estos resultados son semejantes a los de Williams, Kubelik, Livak, Rafalski y Tingey (1990) quienes a concentraciones bajas de ADN molde produjeron una mengua en el número de bandas amplificadas.

El cloruro de magnesio $\left(\mathrm{MgCl}_{2}\right)$ es de gran importancia para la reacción de RAPD-PCR, ya que los iones $\mathrm{Mg}^{2+}$ forman un complejo soluble con los dNTPs, estimulando la actividad de la polimerasa, incrementando la temperatura media de interacción entre la doble cadena de ADN molde y los oligonucleótidos-iniciadores (McPherson y Moller, 2000). Los resultados obtenidos de $\mathrm{MgCl}_{2}$ en este estudio (figura 4B, carril 4) son similares a los de McPherson y Moller (2000) (Hernández, Marinño, Orozco y Narváez, 1997) quienes afirman, que la efectividad de las amplificaciones de marcadores RAPDs es mayor con una concentración final de $3,5 \mathrm{mM}$ de $\mathrm{MgCl}_{2}$, provocando un incremento en el número de bandas y en su intensidad. Hernández et al. (1997) concluyen que las concentraciones menores o iguales a 2,5 mM de $\mathrm{MgCl}_{2}$ generan barridos, como se puede ver en la figura 4B, carriles 1 y 2.

En la figura 5B carriles $3,4,5$ y 6 donde se empleó de tres a seis unidades de Taq polimerasa respectivamente se evidencian barridos después de los $700 \mathrm{pb}$, corroborando lo alcanzado en estudios previos (Sansinforiano et al., 2001). Williams, Hanafey, Rafalski y Tingey (1993) encontraron que el uso de concentraciones de Tag ADN polimerasa mayores a tres unidades, tienden a amplificar fragmentos inespecíficos.

Por otro lado, los fragmentos amplificados claros e intensos aumentaron cuando se disminuyó la concentración de la enzima. La concentración óptima de Taq ADN polimerasa fue de una unidad, resultado que está de acuerdo con los obtenidos por McPherson y Moller (2000) (Hernández et al., 1997) ya que a esta concentración se presenta el mayor número de bandas claras e intensas amplificadas cuando se trata de lograr marcadores RAPDs.

Los oligonucleótidos-iniciadores permiten que la Taq ADN polimerasa inicie el proceso de transcripción en cada uno de los fragmentos libres de ADN, por esta razón, es de suma importancia identificar el umbral de concentración de las dos variables (Williams et al., 1993). El patrón de mejor reproducibilidad fue conseguido aplicando $0,5 \mu \mathrm{M}$ de oligonucleótidos-iniciadores con una unidad de 
Taq polimerasa y $7,85 \mathrm{ng}$ de ADN, amplificando 12 bandas claras y de buena intensidad (figura 5A, carril 5). Hay que tener en cuenta que la hibridación de los iniciadores en reacciones de RAPD-PCR ocurre simultáneamente en varios puntos de la cadena molde, utilizándose con regularidad concentraciones altas de oligonucleótidos (Segnini, 2003), que concuerda con los resultados de este estudio. La temperatura de hibridación de los iniciadores y las concentraciones de magnesio, son los factores que más afectan la intensidad relativa de las bandas amplificadas.

La figura $6 \mathrm{~B}$ muestra en los carriles 1 y 2 (temperaturas de 35 y $36^{\circ} \mathrm{C}$ respectivamente) bandas con barridos entre 800 y 1.600 pb. Cavagnaro y Masuelli (2002) (Newton y Graham, 1994) afirman que temperaturas de hibridación menores a $36^{\circ} \mathrm{C}$ producen apareamientos inespecíficos entre oligonucleótidos-iniciadores y ADN molde, que generan bandas no-específicas de baja reproducibilidad.

En total, se ejecutaron 46 reacciones para la estandarización de marcadores moleculares RAPDs para $C$. caretta, 34 reacciones para la estandarización de todas las variables, cuatro para evaluar la reproducibilidad y ocho reacciones adicionales para valorar la variabilidad producida por igual número de oligonucleótidos-iniciadores. La estandarización y su análisis se llevó a cabo en tres semanas (21 días). Este diseño experimental propuesto ahorra tiempo y dinero y genera resultados óptimos que pueden ser de provecho para evaluaciones poblaciones, para este caso un modelo con la tortuga cabezona.

En total se evaluaron seis concentraciones de DNA, cinco de oligonucleótidos-iniciadores, cinco de $\mathrm{MgCl}_{2}$, cinco de Taq ADN polimerasa y cuatro de temperatura de hibridación de los iniciadores. Se requeriría por métodos convencionales un total de 3.000 reacciones $(6 \times 5 \times 5 \times 5 \times$ 4) para obtener, tal vez, el mismo resultado.

Este modelo de estandarización sirve en estudios de genética de poblaciones con marcadores moleculares y adicionalmente integrarlos en el currículo de biología molecular y/o bioquímica para estudiantes de pregrado y maestría, de esta manera, los alumnos podrían comprender mejor los principios de la PCR, de los marcadores moleculares y la traducción de bandas o perfiles electroforéticos en la matematización de conceptos complejos de la genética de poblaciones animales. 


\section{Conclusiones}

El método Taguchi permite minimizar el número de reacciones en la estandarización de marcadores moleculares RAPD-PCR, en la primera ronda de 81 a nueve reacciones, y luego, para determinar variable por variable de 3.000 a solo 46 reacciones. Se obtuvo una metodología estandarizada para la consecución de marcadores moleculares RAPDs en tortugas marinas Caretta caretta. Los RAPDs obtenidos producen bandas claras, legibles, reproducibles y variables entre ocho oligonucleótidos-iniciadores examinados. Estas condiciones así definidas son válidas para la puesta en marcha de estudios genético-poblacionales en Caretta caretta.

La presencia (1) y ausencia (0) de bandas polimórficas, fue una herramienta práctica para la adquisición de datos cualitativos por una matriz binaria que hizo posible dar aproximaciones de la genética de poblaciones para un modelo de estudio.

Este modelo podría ser aprovechado para integrarlo al currículo de biología molecular y/o bioquímica para estudiantes de pregrado y maestría.

\section{Agradecimientos}

Los autores agradecen a los acuarios Museo del Mar del Rodadero de Santa Marta y al Instituto Ceiner de Islas del Rosario, por ceder las muestras biológicas de la tortuga C. caretta.

\section{Financiación}

Este estudio fue financiado por la Dirección de Investigación, Creatividad e Innovación de la Universidad Jorge Tadeo Lozano.

\section{Conflicto de intereses}

Los autores no presentan conflicto de intereses.

\section{Referencias}

ABREU, A. 2000. Genética poblacional y filogeografía de las tortugas marinas golfina (Lepidochelys olivacea) y laúd (Dermochelys coriacea) en el Pacífico Mexicano. México: Universidad Autónoma de México, Instituto de Ciencias del Mar y Limnología, Estación Mazatlán, Laboratorio de Genética. 
AtienZAR, F., EVenden, A., JHA, A., SAVVA, D., y Depledge, M. 2000. «Optimized RAPD analysis generates high quality genomic ADN profiles at high annealing temperature». En: Biotechniques, 28, $52-54$.

BOWEN, W., y KARL, A. 2007. «Population genetics and phylogeography of sea turtle». En: Molecular Ecology, 16, 4886-4907.

CASTAÑO, O. 2002. Libro rojo de reptiles de Colombia. Bogotá: Instituto de Ciencias NaturalesUniversidad Nacional de Colombia, Ministerio del Medio Ambiente, Conservación InternacionalColombia.

CavagnaRo, P., y MASUelLI, R. 2002. «Optimización de la técnica RAPD para identificar CV de olivo». En: Revista FCA UNCuyo, 1, 107-117.

CeBallos, C. 1996. Plan Nacional para la Conservación de las Tortugas Marina y Continentales con Distribución en Colombia. Bogotá: Subdirección de Fauna, Dirección General Forestal y de Vida Silvestre, Ministerio del Medio Ambiente. Propuesta elaborada en consultoría.

COBB, B., y CLARKSON, J. 1994. «A simple procedure for optimizing the Polymerase Chain Reaction (PCR) using modified Taguchi methods». En: Nucleic Acid Research, 22(18), 3801-3805.

CORPOGUAJIRA. 1992. Estudio de las lagunas costeras en el departamento de La Guajira. Riohacha, Colombia.

DICE, L. 1945. «Measures of the amount of ecological association between species». En: Ecology, 26, 297-302.

DINESH, K., CHAN, W., LIM, T., y PHANG, V. 1995. «RAPD markers in fishes: an evaluation of resolution and reproducibility». En: Asia Pacific Journal of Molecular Biology and Biotechnology, 3(2), 112-118.

DUTTON, P. 1996. «Methods for collection and preservation of sample for sea turtle genetic studies». En: Proceedings of the International Symposium on Sea Turtles Conservation Genetics. NOAA Technical memorandum NMFS-SEFSC-396.

EgUIARTE, L., SoUZA, V., y AGUIRRE, X. 2007. Ecología molecular. México: Secretaría de Medio Ambiente y Recursos Naturales, Instituto Nacional de Ecología, Universidad Nacional Autónoma de México, Comisión Nacional para el Conocimiento y Uso de la Biodiversidad.

FitzSimmons, N., Limpus, C., Norman, J., Goldizen, A., Miller, J., y MoRitZ, C. 1997. «Philopatry of male marine turtles inferred from mitochondrial DNA markers». En: Proceedings of the National Academy of Sciences, 94, 8912-8917.

GeLFAND, D. 1992. «Taq DNA polymerase». En: PCR Technology. Principles and applications for DNA amplification. Nueva York: W.H. Freeman and Company. 
HernándeZ, J., MARINÑo, L., OrozCo, C., y NARVÁEZ, J. 1997. «Uso de la reacción en cadena de la polimerasa para caracterizar aislamientos nativos de Bacillus thuringiensis». En: Revista Corpoica, 2(1), 1-9.

INSTITUTO DE INVESTIGACIONES MARINAS Y COSTERAS (Invemar). 2002. Determinación de la distribución y del estado de conservación de las tortugas marinas en el Caribe colombiano. Informe Final. Santa Marta: Convenio Secab Secab-Invemar.

Jones, C., Edwards, K., Castiglione, S., Winfield, M., Sala, F., Van de Wiel, C., Bredemeluer, G., Vosman, B., Matthes, M., Daly, A., Brettschnelder, R., Bettinl, P., BuiattI, M., Maestri, E., MalceVschi, A., MARmiroli, N., Aert, R., VolCKaert, G., RuedA, J., LinACERo, R., VAzQuez, A., y KARP, A. 1997. «Reproducibility testing of RAPD, AFLP and SSR markers in plant by a network of european laboratories». En: Molecular Breeding, 3, 381-390.

LIU, Z., y CORDES, J. 2004. «DNA marker technologies and their applications in aquaculture genetics". En: Aquaculture, 238, 1-37.

LóPEZ, E., HERNÁNDEZ, J., y BERNAL, J. 2008. «Condiciones óptimas de cultivo de linfocitos y análisis parcial del cariotipo de la tortuga cabezona, Caretta caretta (Testudines: Cheloniidae) en Santa Marta, Caribe colombiano». En: Revista Biología Tropical, 56(3), 1459-1469.

LÓPEZ, M., CARMONA, R., y NICHOLS, W. 2004. «Nesting characteristics of the olive ridley turtle (Lepidochelys olivacea) in Cabo Pulmo, southern Baja California». En: Marine Biology, 145, 811-820.

MARRUGO, Y., y VÁSQUEZ, A. 2001. «Aspectos reproductivos de la tortuga "gogo" Caretta caretta (Linnaeus, 1758) en las playas de Quintana, Don Diego, Buritacá, Guanchaco y Mendiguaca, Caribe Central de Colombia. Informe preliminar». En: Contribución al conocimiento del estado actual de las tortugas marinas y sus hábitats de anidación en los parques nacionales naturales de la Costa Atlántica. Asociación Widecast Colombia, UAESPNN DTCA, Ministerio del Medio Ambiente, Colombia.

MCPHERSON, M., y MoLLER, S. 2000. PCR the basics from background to bench. Oxford: BIOS Scientific Publishers.

Ministerio del Medio AmBIENTE de ColombiA. 2000. Plan de acción para la conservación de las tortugas marinas en el Caribe colombiano. Dirección General de Ecosistemas. Documento manuscrito.

MOORE, M., y BALL, R. 2002. «Multiple paternity in loggerhead turtle (Caretta caretta) nests on Melbourne beach, Florida: a microsatellite analysis». En: Molecular Ecology, 11, 281-288.

NASON, J. 2002. «Estructura genética de las poblaciones de árboles». En: Ecología y conservación de bosques neotropicales. Costa Rica: Eulac-GTZ. 
NEI, M. 1978. «Estimation of average heterozygosity and genetic distance from a small number of individuals». En: Genetics, 89, 583-590.

Newton, C.R., y Graham, A. 1994. PCR. Oxford: BIOS scientific publishers.

Penner, G., Bush, A., Wise, R., Kim, W., Domier, L., Kasha, K., Laroche, A., Scoles, G., Molnar, S., y FEDAK, G. 1993. «Reproducibility of Random Amplified Polymorphic DNA (RAPD) analysis among laboratories». En: Genome Research, PCR Methods and Applications, 2, 341-345.

Poutou, R., BuRBano, M., SierRA, S., ToRRE, M., y MerCADo, M. 2005. «Estandarización de la extracción de ADN y validación de la PCR múltiple para detectar Listeria monocytognes en queso, leche, carne de res y pollo». En: Universitas Scientiarum, 10(2), 61-78.

Sansinforiano, M., Rabasco, A., Martínez, M., Parejo, J., Hermoso, M., y Padilla, J. 2001. «Optimización de las condiciones RAPD-PCR en Candida spp. y Cryptococcus spp». En: Revista Iberoamericana de Micología, 18, 65-69.

SEGNINI, S. 2003. «El uso de los macroinvertebrados bentónicos como indicadores de la condición ecológica de los cuerpos de agua corriente». En: Sociedad Venezolana de Ecología, Ecotrópicos, 16(2), 45-63.

SLATKIN, M. 1987. "Gene flow and the geographic structure of natural populations». En: Science, 236, 787-792.

StaUb, J., y SeRQUeN, F. 1996. «Genetic markers, map construction, and their application in plant breeding». En: Hortscience, 31(5), 729-741.

TAGUCHI, G., y Wu, Y. 1980. Introduction to off-line quality control. Japan: Nagoya: Central Japan Quality Control Organization.

WASHINGTON, B. 1984. «Diversity, biotic and similarity indices. A review with special relevance to aquatic ecosystems». En: Water Research, 18, 653-694.

WELSH, J., y MCCLELLAND, M. 1990. «Fingerprinting genomes using PCR with arbitrary primer». En: Nucleic Acid Research, 18(24), 7213-7218.

Williams, J., HAnAfeY, M., RAfalski, J., y TINGEY, V. 1993. «Genetic analysis using Random Amplified Polymorphic DNA». En: Methods in Enzimology, 218, 704-740.

WILLIAMS, J., KUBELIIK, A., LIVAK, K., RAFALSKI, J., y TINGEY, S. 1990. «DNA polymorphisms amplified by arbitary primers are useful as genetic markers». En: Nucleic Acid Research, 18(22), 6531-6535.

WRIGHT, S. 1978. Variability within and among natural populations. Vol. 4. Chicago: University of Chicago Press. 
YeH, F., YANG, R., y BoYLE, T. 1999. Population genetic analysis, POPGENE VERSION 1.31. Molecular Biology and Biotechnology Centre. Edmonton: University of Alberta, Center for International Forestry Research.

YOON, C., y GLAWE, D. 1993. «Pretreatment with RNase to improve PCR amplification of DNA using 10-mer primers». En: BioTechniques, 14, 908-910. 